\title{
Considerações sobre infância/velhice, memória/linguagem, a partir do conto "Nenhum, nenhuma", de João Guimarães Rosa
}

\author{
Maria Schtine Viana
}

RESUMO: Por meio deste ensaio, pretende-se realizar um exercício de leitura do conto “Nenhum, nenhuma", de João Guimarães Rosa, para verificar em que medida a memória é utilizada não apenas para recuperar um episódio específico ocorrido no passado, mas, sobretudo, para assinalar a importância do papel da reminiscência como elemento deflagrador da inspiração. Tendo em vista uma estrutura circular, em que infância e linguagem parecem remeter uma à outra, cabe também investigar a relação entre velhice/infância na constituição dessa estória.

PALAVRAS-CHAVE: Infância; velhice; memória; linguagem; inspiração.

\begin{abstract}
Through this reading of "None, None", a tale by João Guimarães Rosa, we intend to verify the extent of memory as not only something that recovers a specific episode but, above all, something that reveals the importance of reminiscence as the trigger of inspiration. In view of the circular structure, where childhood and language seem to refer to each other, it is also necessary to investigate the relation between old age/childhood in the constitution of this story.
\end{abstract}

KEYWORDS: Childhood; old age; memory; language. 


\section{PREÂMBULO}

Se, para os gregos, o estudo da retórica pressupunha um método de educação no qual a dialética era, a um só tempo, pesquisa do ser em si e união amorosa da alma no aprender e no ensinar, a verdadeira arte da persuasão retórica, por sua vez, seria a capacidade de guiar a alma na busca da virtude, do bem e da verdade. Se o contato possível com a ideia genuína se daria por meio da reminiscência das verdades, contempladas durante o cortejo divino, recordar-se dessas verdades existentes nesse espaço supraceleste não seria possível para muitos, pois somente alguns seres teriam o dom da reminiscência.

Os dois discursos proferidos por Sócrates em Fedro - ainda que no primeiro afirmasse que não se deveriam conceder favores a quem se ama - têm como tema central o amor, uma espécie de loucura provocada por um impulso divino que ajudaria a alma a se aproximar do Belo. Na acepção platônica, divina também é a inspiração, que pode ser organizada em quatro categorias: a inspiração que levaria ao transe poético, advinda de Apolo; a mística, que provocaria a catarse, propiciada por Dionísio; a poética, concedida pelas Musas; e aquela que deflagra o delírio amoroso, atribuída a Afrodite e Eros. ${ }^{1}$ Considerada por Sócrates nesse diálogo como forma de inspiração excelente, esta última fora usada como modelo para ensinar sobre o bem falar e escrever.

Em Fedro, Platão, tomando as impressões do rei Tamos sobre a invenção do deus Theuth, afirma que a escrita tornaria as almas mais esquecidas, pois os homens passariam a confiar em caracteres externos, em vez de tomarem como verdade o que, graças ao próprio empenho, vem de dentro. ${ }^{2}$ Logo, a escrita seria uma espécie de auxiliar para a recordação. Mas suprimiria a reminiscência, ${ }^{3}$ não sendo, portanto, um bom remédio

1. Platão. Fedro. Tradução de José Ribeiro Ferreira. Lisboa: Edições 70, 2009, p. 99.

2. Idem, p. 120.

3. Em Filebo, Sócrates defende a ideia de que, quando a alma recebesse alguma impressão juntamente com o corpo e, depois sozinha por si mesma, conseguisse recuperá-la tanto quanto possível, essa sensação receberia o nome de reminiscência. "A memória, em consonância com as sensações que dizem respeito àquelas ocorrências, é como se escrevesse, por assim dizer, discurso na alma; e quando o sentimento da ocorrência escreve certo, então se forma em nós opinião verdadeira da qual também decorrem discursos verdadeiros, porém quando o escrevente que temos dentro de nós escreve errado, produz-se precisamente o contrário da verdade." Portanto, nesse diálogo, Sócrates concebe o livro como a alma e, por conseguinte, a memória como uma espécie de escriba que grafa algo na alma. PLATÃo. Filebo. Texto estabelecido e anotado por John Burnet. Tradução, apresentação e notas de Fernando Muniz. Rio de Janeiro: Ed. PUC-Rio; São Paulo: Loyola, 2012. 
para a memória. Nesse diálogo platônico, o livro aparece explicitamente na forma do rolo de papiro, em que está registrado o discurso de Lísias, lido por Fedro. Mas Sócrates reitera que, tanto para o bem falar como para o bem escrever, é imprescindível o uso das Verdades, provenientes das reminiscências que a alma imortal carrega, desde que tenha podido contemplar o Belo no espaço supracelestial. Portanto, para conhecer bem a verdade de cada coisa e não seguir apenas a opinião alheia, como seria o caso das almas não agraciadas com o dom da reminiscência, seria preciso deixar-se guiar pela loucura criativa e amorosa, pois é por esse estado de "reminiscência do Belo que se enche a alma de alegria".

Mas qual seria o papel da inspiração e da reminiscência no conto "Nenhum, nenhuma”, de João Guimarães Rosa? Em uma estrutura circular, em que infância e linguagem parecem remeter uma à outra, pode-se arriscar dizer que nesse conto a infância age sobre a linguagem, constituindo-a de maneira peculiar, sendo essas misteriosas experiências possíveis devido ao fato de todo ser humano ter tido uma infância? Essas questões serão tangenciadas nas páginas seguintes.

Começo estas reflexões compartilhando a constatação de que a oitava posição do conto "Nenhum, nenhuma" entre as 21 narrativas da coletânea Primeiras estórias, de João Guimarães Rosa, que veio a lume em 1962, por certo não é casual. Basta lembrar que o escritor que usava com regularidade o símbolo do infinito $(\infty)$, presente tanto nas imagens encomendadas ao artista Luís Jardim para ilustrar as vinhetas do sumário do livro supracitado, como no fechamento de sua obra mais conhecida e estudada, Grande Sertão: Veredas.

Os eventos desse conto, escolhido para este exercício de pensamento, ocorrem em uma casa, localizada à beira da mata de algum rio. Ali, por meio da memória, adentra um menino no primeiro aposento, o escritório. $\mathrm{O}$ infante, que ainda não sabe ler, em um ato sinestésico, "relê" numa revista o cheiro colorido das imagens. É por intermédio da Moça, filha do homem "já entrado em anos" e dono da casa, que nos é dada a conhecer a data, 1914, que "sempre a voz da Moça retificava"."

4. Idem, p. 68.

5. ROSA, João Guimarães. Primeiras estórias. Rio de Janeiro: Nova Fronteira, [1962] 2005, p. 94. 
Se as datas não costumam ser recorrentes nas narrativas rosianas, deve-se considerar a importância dessa marca temporal, pois em julho daquele ano deflagrou-se a Primeira Guerra Mundial. Cabe lembrar que, de acordo com Walter Benjamin, as experiências entraram em crise justamente depois dessa guerra, pois "[...] nunca houve experiências mais radicalmente desmoralizadas que a experiência estratégica pela guerra de trincheiras". ${ }^{6}$ Todavia, João Guimarães Rosa, que, aliás, exerceu funções de diplomata na Alemanha nessa época, constrói estórias em que os narradores imperam, e o tempo é apreendido e recomposto como direção e sentido da experiência.

No conto "Nenhum, nenhuma", um Menino observa o encontro entre o Moço e a Moça. Por certo estão apaixonados, mas uma tensão suspende a narrativa. O Moço está ali, ansioso, em busca de uma resposta; pressupõe-se que espera receber um "sim" da Moça. No entanto, trechos de conversas lembrados pelo Menino - que, se recordar, "ganhará calma", mas para consegui-la é preciso religar-se, "adivinhar o verdadeiro" (p. 94) - revelam que há um impedimento. Não a morte do pai dela, condenado por alguma doença fatal, ou da velhinha Nenha, de quem ela cuidava, mas da morte deles mesmos, da Moça e do Moço. Ela quer ser lembrada no "para sempre", deste e de outro tempo. Então, o que a jovem requisita não é a certeza do amor. O que ela deseja é não ser esquecida no jamais. Seria possível? O Moço não está certo de que pode responder a essa demanda e parte na companhia do Menino. Temos, assim, a história aparente: a impossibilidade de um final feliz entre dois jovens amorosos devido ao não querer da Moça, que deseja mais do que o Moço pode ou quer oferecer. ${ }^{7}$

Mas se mesmo um menino sabe que "às vezes é preciso desconfiar do estreito caminhozinho por onde a gente tem de ir” (p. 95), vê-se que será necessário (re)ler outras camadas do conto.

Doravante se indicarão, entre parênteses, as páginas do conto estudado.

6. Benjamin, Walter. Magia e técnica, arte e política. Tradução de Sérgio Paulo Rouanet. São Paulo: Brasiliense, 1985, p. 115.

7. Cabe apontar o conto "Arroio-das-Antas", que figura em Tutameia, protagonizado por Drizilda. Depois de ter o marido assassinado por seu irmão, a jovem vai parar em uma fazenda nos rincões do sertão, onde só restavam velhos. É acolhida e cuidada por sobejas velhinhas, que rezavam pela boa sorte da protegida. Entretanto, diferente do desfecho de "Nenhum, nenhuma”, o Moço, que certo dia por lá aparece, recebe um "sim" como resposta. Essa narrativa é coroada com um final feliz, nos moldes de um conto maravilhoso: "Assim são lembrados em par os dois - entreamor - Drizilda e o Moço, paixão para toda a vida" (ROSA, João Guimarães. Tutameia. Rio de Janeiro: Nova Fronteira, 2017, p. 41). 
O vagaroso movimento da Moça, escondido nas dobras da memória do Menino, pode guiar o leitor que se habilite a fazer várias leituras. É preciso, como adverte Lyotard, ler devagar, pois "a escrita e a leitura são vagarosas, avançam para trás, na direção da coisa desconhecida 'no interior"'.

Acompanhando o olhar do Menino, entra-se novamente na casa, primeiro no escritório. Avista-se a mesa grande, de madeira vermelha, cheirosa, vislumbram-se o homem "entrado em anos" e o Menino a folhear a revista. Logo alguém mais entrará ali: a Moça, bela, alta, a alvura da pele ainda mais realçada pelo preto vestido. Sua presença é associada a um sentimento de paz, ou melhor, ao "que está por trás da palavra 'paz"' (p. 94). O narrador continua a lutar com a memória, insiste em querer saber o motivo de o Menino ter ido parar naquela casa, sem pessoas da sua família, e, talvez, só porque tivera de permanecer por mais tempo ali, deixaram-no ver o que, como um segredo, em certo quarto se guardava.

É evidente o susto do infante ao avistar pela primeira vez Nenha, que "Era uma velha, uma velhinha - de história, de estória - velhíssima, a inacreditável” (p. 95). ${ }^{9}$ Entretanto, é imperativo que o leitor atento reconheça nela os atributos de um recém-nascido: pequenina conforme uma criança, não caminhava nem ficava de pé. De onde procedia Nenha?

Dela, está claro, ninguém mais sabe o nome, tampouco a origem. Vinha através de gerações, consoante as próprias estórias contadas e recontadas pelos narradores. $\mathrm{O}$ conhecimento sobre a origem de Nenha teria morrido com as mulheres de "roca e fuso"? Ou está o narrador sinalizando que as experiências não poderiam mais ser narráveis depois de 1914? Os adventos da História seriam mesmo um impedimento para a sobrevivência das estórias?

8. LYOTARD, Jean-François. O inumano: considerações sobre o tempo. Tradução de Ana Cristina Seabra e Elisete Alexandre. Lisboa: Estampa, 1990, p. 10.

9. A relação entre infância/velhice é recorrente em outras obras de Guimarães Rosa. Basta lembrar as narrativas do ciclo Corpo de baile. Ali a presença das personagens Miguilim e Manuelzão, protagonistas das duas primeiras estórias, já evidencia o binômio infância/velhice. Esse aspecto é verificável também no encontro entre o boiadeiro Lélio e a velha Lina. Quando avistada pela primeira vez por Lélio, dona Rosalina parece-lhe ser uma mocinha. Papel relevante tem ainda o menino Joãozezim, um dos mensageiros do "Recado do morro", ao dar ouvidos à conversa do velho Catraz. Em "Buriti", os jogos de sedução entre Lalinha e Iô Liodoro também remetem ao binômio juventude/velhice; bem como a relação entre Grivo e Cara-de-Bronze. 
É a necessidade de estabelecer contato com as remotas lembranças de infância, buscadas nos rastros de acontecimentos que exigem um trabalho de reelaboração, que impera na tessitura desse conto, e não um narrador, tão presente fisicamente em outras narrativas de Rosa. Conforme bem aponta Rowland, em muitas narrativas rosianas "o lugar da história, o lugar do conto, é ainda o corpo do narrador, que resiste e se impõe, ao mesmo tempo que instaura uma 'verdadeira parte' que dele não se pode desprender". ${ }^{10}$

O primeiro encontro do Menino com Nenha, resguardada em seu quarto, deflagra uma longa tentativa de recordação e um trabalho de associação de ideias, que lembra a livre associação, proposta por Freud e retomada por Lyotard. Recurso que se pode constatar no trecho seguinte:

Tênue, tênue, tem de insistir-se o esforço para algo remembrar, da chuva que caía, da planta que crescia, retrocedidamente, por espaço, os castiçais, baús, arcas, canastras, na tenebrosidade, a gris pantalha, o oratório, registros de santos, como se um pedaço de renda antiga, que se desfaz ao se desdobrar, os cheiros nunca mais respirados, suspensas florestas, o porta-retratos de cristal, floresta e olhos, ilhas que se brancas, as vozes das pessoas, extrair e reter, revolver em mim, trazer a foco as altas camas de torneado, um catre com cabeceira dourada; talvez as coisas mais ajudando, as coisas, que mais perduram: o comprido espeto de ferro, na mão da preta, o batedor de chocolate, de jacarandá, na prateleira com alguidares, pichorras, canecas de estanho (ROSA, 2005, pp. 95-6). ${ }^{11}$

Assustado, o Menino foge para a cozinha da casa, de onde é buscado pela Moça e pelo Moço.

Benedito Nunes apresenta Nenha como se fosse "O espectro da morte interposto entre ela [a Moça] e o Moço que a ama”." Todavia, fica claro no próprio conto que

10. Rowland, Clara. A forma do meio. São Paulo: Edusp, 2011, p. 106.

11. João Guimarães Rosa em carta destinada a seu tradutor alemão, Curt Meyer-Clason, insiste para a importância de destacar as palavras por ele assinaladas nesse conto: "No conto 'NENHUM, NENHUMA', é necessário sublinhar, ou pôr em grifo, as partes que sublinhei com lápis verde. Isto é indispensável, importantíssimo. Aquelas passagens, entremeadas, correspondem a outro plano: representam o esforço do narrador, em solilóquio, tentando recapturar a lembrança do que se passou em sua infância. Tá?”. RosA, João Guimarães. Correspondência com seu tradutor alemão, Curt Meyer-Clason (1958-1967). Rio de Janeiro: Nova Fronteira, ABL; Belo Horizonte: UfMG, 2003, p. 304.

12. NUnEs, Benedito. "O amor na obra de Guimarães Rosa". In: A Rosa o que é de Rosa: literatura e 
a velhinha não era assombração, nem a morte, tampouco estava morta: "Antes era a vida. Ali num só ser, a vida vibrava em silêncio, dentro de si, intrínseca, só o coração, o espírito da vida, que esperava" (p. 96).

\section{III}

De acordo com Derrida, "Um texto só é um texto se ele se oculta ao primeiro olhar, ao primeiro encontro, a lei de sua composição e a regra de seu jogo. [...] A dissimulação da textura pode, em todo caso, levar séculos para desfazer seu pano". ${ }^{13}$ Então, podemos ensaiar outra possibilidade de leitura: seria Nenha uma espécie de guardiã da palavra sentida antes de ser escrita? Além de podermos ler a palavra Nenha como uma explícita redução do pronome indefinido nenhuma, que aparece no título, a palavra lembra um balbucio que antecede a capacidade de articulação da fala pela criança. A velhinha descende de uma tradição de mulheres de "roca e fuso". Para Benjamin, um dos contextos que favoreciam a aquisição e a transmissão de narrativas orais era justamente o universo arcaico dos tecelões: "Assim se teceu a rede em que está guardado o dom narrativo". ${ }^{14}$ No entanto, paradoxalmente, Nenha quase já não falava. Em "Nenhum, nenhuma" o tear, que metaforiza a rede aberta da tradição oral, não é recuperado pela palavra falada, mas pelas lembranças, que, por sua vez, tomam forma na escrita.

Se para Agamben, "[...] a instância de discurso é desde o início confiada à memória, mas de tal modo que memorável é a própria inapreensibilidade da instância de discurso enquanto tal (e não simplesmente uma instância de discurso historicamente e espacialmente determinada), que funda assim a possibilidade de uma infinita repetição", ${ }_{15}$ pode-se inferir que Nenha era a palavra que esperava tornar-se vida por meio do escrito, pois com seu esquecimento se perderiam os conhecimentos de uma tradição de narradores.

Sabe-se que, por meio de sua escrita, João Guimarães Rosa conduz o leitor a refletir sobre a palavra, até conseguir extrair dela outro entendimento, e não apenas a

filosofia em Guimarães Rosa. Org. Victor Sales Pinheiro. Rio de Janeiro: Difel, 2013, p. 63.

13. DERRIDA, Jacques. A farmácia de Platão. Tradução de Rogério da Costa. São Paulo: Iluminuras, 1991, p. 7.

14. BENJAMIN, Walter. Op. cit., p. 115.

15. Agamben, Giorgio. "Sétimo dia". In: Floresta encantada: novos caminhos da literatura comparada. Lisboa: Dom Quixote, 2001, pp. 586-7. 
compreensão do enredo da história que está a ser contada. ${ }^{16}$ É certo que, em "Nenhum, nenhuma", um narrador adulto busca nas reminiscências de um passado remoto as evidências de um encontro entre dois jovens apaixonados, e aborda a impossibilidade de realização desse amor. Todavia, podemos também inferir que nessa estória a infância não é apenas a marca de uma fase inicial da vida humana; poderia a memória recuperar um tempo imemorial? Dito de outra forma, haveria no projeto rosiano esse desejo, já que, de acordo com Agamben, "O imemorial, que se precipita de memória em memória sem nunca chegar à recordação, é verdadeiramente inesquecível. Esse esquecimento inesquecível é a linguagem, é a palavra humana"? ${ }^{17}$

Nesse trabalho de perlaboração, o narrador empenha-se em escutar seus sentimentos. Esse proceder aproxima o Menino pouco a pouco dos fatos perdidos em algum lugar do passado. Com isso quero dizer que, nessa estória, o passado é também protagonista, recomposto pela memória não apenas do vivido e lembrado, ou talvez, do sonhado, mas também reescrito poeticamente como estória narrável. Por conseguinte, essa recordação já não faz parte do passado, é presente, e, dessa maneira, é vivido por aquele que recorda. Ao desmontar a retórica do inconsciente pelo escrito, o vivido faz-se presente.

Nesse jogo entre imaginário e memória, é necessário deixar que as coisas venham da forma como se apresentam para que a narrativa possa ser tecida. Claro que, conforme demonstra Lyotard, no trabalho analítico a perlaboração é um mecanismo por meio do qual o analisando se aproxima da verdade inapreensível, enquanto no artista

\footnotetext{
16. Conforme dito pelo próprio escritor em trecho da entrevista concedida a Günter Lorenz em 1965: "Primeiro, há meu método que implica a utilização de cada palavra como se ela tivesse acabado de nascer, para limpá-la das impurezas da linguagem cotidiana e reduzi-la a seu sentido original. Por isso, e este é o segundo elemento, eu incluo em minha dicção certas particularidades dialéticas de minha região, que são linguagem literária e ainda têm sua marca original, não estão desgastadas e quase sempre são de uma grande sabedoria linguística. Além disso, como autor do século xx, devo me ocupar do idioma formado sob a influência das ciências modernas e que representa uma espécie de dialeto. E também está à minha disposição esse magnífico idioma já quase esquecido: o antigo português dos sábios e poetas daquela época dos escolásticos da Idade Média, por exemplo, em Coimbra. E ainda poderia citar muitos outros, mas isso nos levaria muito longe. Seja como for, tenho de compor tudo isso, eu diria 'compensar', e assim nasce então meu idioma que, quero deixar claro, está fundido com elementos que não são de minha propriedade particular, que são acessíveis igualmente para todos os outros". "Diálogo com Guimarães Rosa”. In: RosA, João Guimarães. Obras completas. Rio de Janeiro: Nova Aguilar, 1994, vol. 1, p. 46. 17. Agamben, Giorgio. Infância e história. Tradução de Henrique Burigo. Belo Horizonte: Editora da UFMG, 2008, p. 58.
} 
"o prazer estético abate-se sobre seu espírito como uma graça, uma inspiração". ${ }^{18}$ No caso desse conto, uma inspiração moderada pelo amor, visto que deflagrada pelo delírio amoroso, e atribuída a Afrodite e a Eros, na categorização platônica.

Logo, em "Nenhum, nenhuma" a infância poderia ser também aquela infância mesma da palavra, guardada conforme um segredo em um quarto no qual o Menino inicialmente é impedido de entrar, e que depois é exposta à luz do dia, na varanda, em berço, como se criança fosse, a ponto de o infante querer com ela brincar. Lembremos que de velha, velhíssima, "de história, de estória", a personagem ganha características de um recém-nascido, acomodado em um cesto. Ela não fala, balbucia, ${ }^{19}$ e esse falar é docemente incompreensível "no semissussurro mais discreto que o bater da borboletinha branca” (p. 97). A Moça é a única que compreende sua linguagem e lhe oferece água. É lá, onde as palavras faltam, que o narrador recupera não só a memória de um fato perdido na infância, mas também experimenta a própria linguagem.

Se é na infância que "a experiência transcendental da diferença entre língua e fala abre pela primeira vez à história seu espaço", ao reentrar na infância por meio da memória, o narrador adulto que escreve a estória "Nenhum, nenhuma" reingressa no balbucio da infância, não de uma infância qualquer, mas de um estado de infância ele mesmo inscrito num círculo em que uma anciã está em estado ainda mais infante que o Menino, já falante, visto que ela, semelhante a um recém-nascido, apenas balbucia. Se o "oblívio da diferença entre língua e fala é o evento fundador da metafísica", ${ }^{20}$ pode-se

18. LYOTARD, Jean-François. Op. cit., p. 41.

19. Agamben retoma como exemplo uma experiência mística praticada na Antiguidade grega, em que o páthema era uma espécie de antecipação da morte, e morrer, teleutãn, e ser iniciado, teleísthai, seriam a mesma coisa. Diz ainda que "o centro da experiência dos mistérios era não um saber, mas um sofrer (ou "mathein, allá pathein", nas palavras de Aristóteles), e se este páthema era, na sua essência, subtraído à linguagem, era um não poder-dizer, um murmurar com a boca fechada, então esta experiência era bastante próxima de uma experiência da infância do homem”. A partir do século IV d.C., continua Agamben, "O mundo antigo interpreta esta infância mística como um saber acerca do qual se deve calar, como um silêncio resguardado [...]. O páthema torna-se aqui máthema; o não poder-dizer da infância, uma outra doutrina secreta sobre a qual pesa um juramento de silêncio esotérico. [...] Daí a importância da fábula, esse lugar 'em que mediante a inversão das categorias boca fechada/boca aberta, pura língua/ infância, o homem e a natureza trocam seus papéis antes de reencontrarem a parte que lhes cabe na história"'. (Cf. AGAMBEN, Giorgio, op. cit., pp. 77-8).

20. Idem, p. 71. 
pensar que, na tentativa de recuperar o esquecido, Guimarães Rosa tangencia esse hiato entre língua e fala e formula essa diferença de tal maneira que a linguagem chega ao seu limite incontrolável e se transforma em filosofia, convidando seu leitor a "esperar o terceiro pensamento" (p. 10o). Travessia infinita.

\section{EPÍLOGO}

O resplendor das brasas só vem depois do assoprado das cinzas e se, de acordo com o escritor mineiro, "o idioma é a única porta para o infinito, mas infelizmente está oculta sob uma montanha de cinzas", este exercício de análise permitiu-me verificar que, ao lutar com a memória em busca dessa ancestralidade da palavra perdida, o pensamento do escritor "está ali emaranhado em não pensamento, tentando desemaranhar a língua perdida da infância”.

Se podemos pensar que, de um lado, temos o par Moça-Nenha, representantes da palavra ainda não pronunciada, mas que não pode ser esquecida, e, de outro, o duplo MoçoMenino, os que foram desafiados a lembrarem-se do ainda não proferido, não por acaso o escritório é o primeiro e o último cômodo da morada que visitamos na companhia do narrador: trata-se do espaço da palavra escrita, ou, melhor, onde a palavra é escrita. Nesse cômodo, na primeira cena, o Menino folheia uma revista, pois ainda não sabe ler. Depois, já transformado pelo experimentado, o Moço escreve ali um bilhete endereçado à Moça.

A circularidade desse percurso - em que inicialmente a palavra escrita não é decodificada, pois o Menino apenas folheia a revista, e na sequência tem lugar um escriba, que escreve um recado de despedida - também nos possibilita inferir que essa personificação do Menino-Moço passa de um estado de não domínio do escrito, e maior proximidade da oralidade, para o escrito, porém um escrito tocado pela tradição preservada pela oralidade.

Então, podemos retomar Platão, que distingue recordação e memória. Lembremos que Sócrates explica a Fedro que a escrita é um bom remédio para a recordação, mas não para a memória; portanto, o que não está escrito na alma é facilmente esquecido. Nesse conto, o passado é o agente que fornece, pela perlaboração, elementos com os quais a narrativa é construída, mas essa escrita por certo foi grafada na alma antes de tomar forma de estória no papel.

É esse rastro indeterminado de "uma infância que persiste mesmo na idade adulta”, ${ }^{21}$ e que faz da criança eminentemente humana, que, neste conto, permite os possíveis

21. LYOTARD, Jean-François. Op. cit., p. 102. 
da criação. Se a morte é o limite, e por excelência aquilo que tentamos adiar, o circuito ganha outra dimensão, quando o Moço por não ouvir o sim, mas um "não", parte levando consigo o Menino. Contudo, como um novelo do qual é preciso estender o fio para tecer a trama, essa negação não é definitiva, uma vez que, por meio do fio da memória, os fatos são recuperados e entretecem a palavra narrada.

Dessa maneira, o aparente "não" é substituído pelo "sim". E se o que a Moça, ela também "menina ancianíssima", guardadora da palavra, desejava era não ser esquecida, por certo não foi, imortalizou-se em estória, recuperada literariamente a partir de fragmentos da reminiscência.

Maria Schtine Viana é mestre em Culturas e Identidades Brasileiras pelo Instituto de Estudos Brasileiros da Universidade de São Paulo (IEB-USP), doutoranda no departamento de Estudos Portugueses da Faculdade de Ciências Sociais e Humanas da Universidade Nova de Lisboa, onde desenvolve pesquisa sobre Corpo de baile, de João Guimarães Rosa. 